Article

\title{
Performance of an Anaerobic Baffled Filter Reactor in the Treatment of Algae-Laden Water and the Contribution of Granular Sludge
}

Yaqin Yu ${ }^{1,2}$, Xiwu Lu ${ }^{1, *}$ and Yifeng $\mathrm{Wu}^{1}$

1 School of Energy and Environment, Southeast University, Nanjing 210096, China;

E-Mails: yad981@163.com (Y.Y.); shinfun@seu.edu.cn (Y.W.)

2 Department of Civil Engineering, Yancheng Institute of Technology, Yancheng 224003, China

* Author to whom correspondence should be addressed; E-Mail: xiwulu@seu.edu.cn;

Tel.: +86-25-8379-2614; Fax: +86-25-8379-5618.

Received: 9 November 2013; in revised form: 23 December 2013 / Accepted: 30 December 2013 / Published: 7 January 2014

\begin{abstract}
This study investigated the performance and stability of an anaerobic baffled filter reactor in the treatment of algae-laden water from Taihu Lake at several organic loading rates. The study also evaluated the capability of soft filler to train granule sludge and improve the anaerobic environment and sludge activity in the anaerobic baffled reactor (ABR), thereby enhancing the treatment efficiency. The ABR consisted of five rectangular compartments, each of which was $120 \mathrm{~cm}$ long, $80 \mathrm{~cm}$ wide, $80 \mathrm{~cm}$ high, and packed with soft filler. The anaerobic baffled filter reactor was found to be an efficient reactor configuration for the treatment of algae-laden water. The reactor was operated at an organic loading rate of $1.5 \mathrm{~kg}$ chemical oxygen demand $(\mathrm{COD}) /\left(\mathrm{m}^{3} \mathrm{~d}\right)$ and an ambient temperature of $30{ }^{\circ} \mathrm{C}$; under these conditions, the COD removal efficiency was $80 \%$ and the biogas production rate was $293 \mathrm{~mL} /(\mathrm{Ld})$. Moreover, the soft filler increased the biomass retention time and decreased the rate at which solids were washed out from the reactor, promoting an improved spatial distribution of the microbial communities within the compartments. Methanoregula, Methanobacteriaceae, Methanosaeta, Methanoculleu, and Thermogymnomonas were the dominant archaeal species in each compartment during an operational period of approximately 100 days. The protease activity in the reactor decreased longitudinally down the reactor from Compartments 1 to 5 , whereas the activity of coenzyme $\mathrm{F}_{420}$ increased. The soft filler played a key role in successfully treating algae-laden water with the anaerobic baffled filter reactor.
\end{abstract}


Keywords: anaerobic baffled reactor (ABR); algae-laden water; soft filler; partial phase separation

\section{Introduction}

The presence of excess nutrients, especially phosphorus and nitrogen, in lakes and reservoirs has been a major factor stimulating blue-green algal blooms [1]. Taihu Lake, which is the third largest lake in China and a source of drinking water for more than two million people in Jiangsu Province, has exhibited serious water toxicity problems due to eutrophication [2]. Water pollution caused by the excessive growth of blue-green algae has become a growing environmental problem. One current approach to reducing the algae in Taihu Lake is to refloat the algae after a bloom has occurred $[3,4]$. A salvage ship takes up water-laden algae in quantities that can reach several thousand cubic meters per day. However, these large quantities of algae-laden water could have serious secondary environmental effects, including the pollution of groundwater, air, and soil without sufficing and effective algae-laden water treatments [5].

Blue-green algae cells are typically rich with polysaccharides and contain a lower cellulose concentration than lignin. Furthermore, blue-green algae cells can be easily degraded to methane during anaerobic digestion processes. Therefore, anaerobic digestion offers key advantages in the treatment of algae-laden water, such as energy production and pollutant removal. Furthermore, the biogas generation rate of algae degradation given in previous research is typically more feasible than that of other recovery methods, such as incineration and composting $[5,6]$.

The design and operation of reactors has been studied to develop anaerobic biotechnology for algae-laden water treatment. Various anaerobic reactors, such as the anaerobic filter (AF), up flow anaerobic sludge blanked reactor (UASB), anaerobic continuous stirred tank reactor (CSTR), and anaerobic baffled reactor (ABR), have been tested and shown to be effective in the literature. In particular, the ABR offers several advantages over traditional reactors, including granulation promotion and phase separation, because of the reactor's unique design characteristics. The ABR also allows acidified hydrolyzation to predominate in the anterior compartment section and methanogenesis to dominate in the subsequent section $[7,8]$.

Scum consisting of suspensions algae is easily formed in digesters, which increases the risk of algae agglomeration and clogging due to the gas-filled sacs in algae. Filling an ABR with a soft filler, such as assembled fiber filler, can prevent the floatation of algae in the reactor.

Previous studies have demonstrated that source water can be purified in a eutrophic lake using indigenous enrichment microbes with a soft filler. Such a purification system was used in Taihu Lake, and the enrichment microbes on the soft filler were found to effectively degrade the lake's algae and microcystins [9]. Biomass in the reactor may be further retained with the addition of soft filler, which could promote biofilm formation and granular sludge cultivation. Therefore, this study aimed to explore the feasibility and performance of an ABR in treating algae-laden water and to determine the capability of soft filler to enhance granule formation and promote phase separation in the ABR during the treatment of algae-laden water. 


\section{Materials and Methods}

\subsection{Experimental Devices}

A 80-cm-wide, 120-cm-long, 80-cm-high ABR was constructed using polyvinylchloride to treat algae-laden water at an active volume of 740L. The ABR consisted of five rectangular compartments, labeled Compartments 1, 2, 3, 4 and 5; the volumes of these compartments were 200, 180, 120, 120, and $120 \mathrm{~L}$, respectively. Downflow and upflow chambers were created within each compartment using an additional baffle. The widths of the downflow and upflow chambers of Compartments 1 and 2 were 10 and $45 \mathrm{~cm}$, respectively. The widths of the downflow and upflow chambers of Compartments 3, 4, and 5 were 9 and $24 \mathrm{~cm}$, respectively. The five compartments were packed with soft filler made of fiber filler with a diameter of $2 \mathrm{~cm}$. The soft filler was made by the Yixing Dushan Environmental Protection Equipment Company. This soft filler had a high specific surface area of up to $2000 \mathrm{~m}^{2} / \mathrm{m}^{3}$. Furthermore, the filler enabled biomass retention by attachment and was able to entrap algae from the algae-laden water. The lower parts of the hanging baffles were angled at $45^{\circ}$ to evenly direct the flow into the center of the upflow chamber. This configuration facilitated effective mixing and contact between the wastewater and anaerobic sludge at the base of each upflow chamber [10]. Each compartment was equipped with sampling ports that allowed biological solids, gas, and liquid samples to be withdrawn. The liquid sampling ports were located $100 \mathrm{~mm}$ from the top of each compartment and the sludge sampling ports were at the bottom of each compartment. Biogas was collected separately via a porthole in the top of the reactor. During the experimental period, the volumes of biogas in the compartments were measured daily using a wet gas meter (Model LML-1, Changchun Filter Co., Ltd., Changchun, China), and the influent feed to the ABR was controlled by a peristaltic pump (Model BT100-01, Baoding, China). The reactor was housed in a temperature-controlled room maintained at $30^{\circ} \mathrm{C}$. Figure 1 provides a schematic of the anaerobic baffled filter reactor.

Figure 1. Schematic of the anaerobic baffled filter reactor.

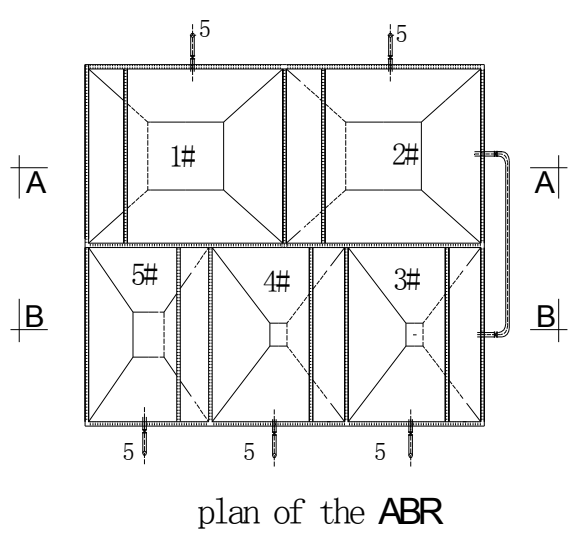

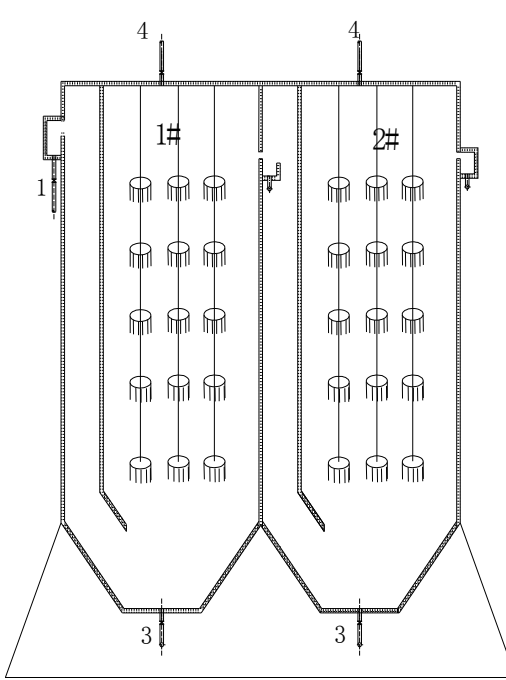

section A-A

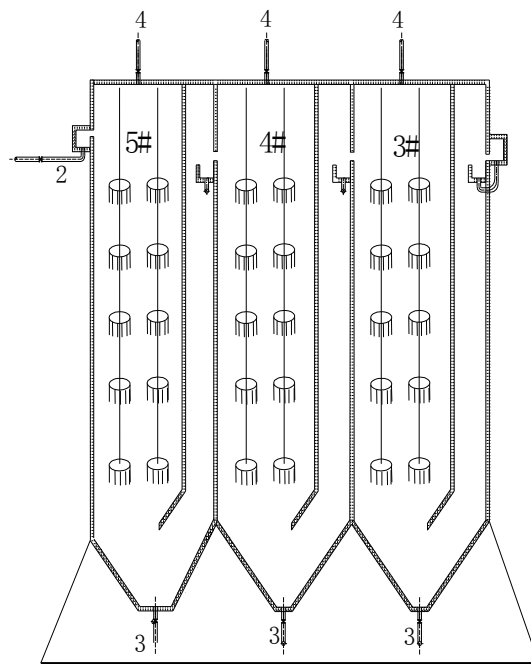

section B-B

1、 inlet pipe; 2、 outlet pipe; 3、 sludge pipe; 4、 gas collection pipe; 5、 sampling pipe 


\subsection{Wastewater Characteristics}

The algae-laden water used in this investigation was freshly collected from a blue-algae refloating site near Taihu Lake, Yixing City, Jiangsu Province, China, at the end of June 2012. The raw water, with a $\mathrm{pH}$ of 5.8-7.3, had a chemical oxygen demand (COD) of 3000-7000 $\mathrm{mg} / \mathrm{L}$, total suspended solids (TSS) of 365-1002 mg/L, total nitrogen (TN) of 55-125 mg/L, and total phosphorus (TP) of 125-183 mg/L. The algae-laden water was diluted using water from Taihu Lake to reach the required concentration.

\subsection{Seed Sludge}

The ABR was initially seeded with sewage sludge, which was collected from a UASB used to treat algae-laden water, thus shortening the cultivation time. Debris and large particles were removed from these wage sludge with a $3-\mathrm{mm}$ sieve. The ratio of mixed liquor volatile suspended solids (MLVSS) to mixed liquor suspended solids (MLSS) in the inoculated sewage sludge was 0.75 ; the sewage sludge was introduced uniformly into the ABR's five compartments. The sewage sludge concentration in each compartment was $28.5 \mathrm{~g}$ MLVSS/L after inoculation.

\subsection{Operation of the Anaerobic Baffled Reactor}

After inoculation, the reactor was sealed and the headspace above each compartment was flushed with nitrogen gas to displace residual air from the system. Initially, the algae-laden water was diluted with water from Taihu Lake to reduce the COD. The reactor was allowed to stabilize for 10 days before the experiments were started to stimulate biofilm growth on the soft filler in each compartment. The experiment performed in this study was then divided into three stages. During each stage, the steady state was marked by relatively stable effluent $\mathrm{pH}$ values and COD values, with variations of less than $5 \%$. At the beginning of the start-up, the reactor was operated at low organic loading to acclimate the sludge. The hydraulic retention time (HRT) was held constant at 10 days, and the concentration of the feed was varied from 500 to $2500 \mathrm{mg} / \mathrm{L}$. The reactor was then operated for 60 days during the second stage to investigate the performance. In this stage, an organic loading rate (OLR) ranging from 0.26 to $1.2 \mathrm{~kg} \mathrm{COD} /\left(\mathrm{m}^{3} \mathrm{~d}\right)$ was achieved by increasing the influent concentration to $6000 \mathrm{mg} / \mathrm{L}$ and decreasing the HRT from seven to five days. A shock experiment was completed within one month during the third stage. The feed's COD concentration was increased to $7200 \mathrm{mg} / \mathrm{L}$ to determine the stability of the reactor treating the algae-laden water.

\subsection{Analytical Methods}

\subsubsection{Chemical Analysis}

The total COD, MLSS, MLVSS, $\mathrm{pH}$, and oxidation-reduction potential (ORP) were measured using standard methods [11]. The total volatile fatty acids (VFAs) were detected in membrane-filtered samples $(0.45 \mu \mathrm{m})$ using gas chromatography (GC, Agilent 4890D) with a flame ionization detector (FID) and a 2-m stainless column packed with Porapak GDX103 (60/80 mesh) [11]. Sludge samples 
were collected from each compartment of the reactor after stable operation for 90days, and the biomass was examined using scanning electron microscopy (SEM) [12].

The biogas composition $\left(\mathrm{CH}_{4}, \mathrm{CO}_{2}\right.$, and $\left.\mathrm{N}_{2}\right)$ was analyzed using gas chromatography with a multigas analyzer (Model GC-2001) [13]. The COD, pH, ORP, and biogas yield were monitored daily, and the enzymatic activity in the sludge was measured once per week during the experimental period. The VFAs and biogas constituents were measured when the reactor reached steady-state conditions.

\subsubsection{Determination of Protease and Co-Enzyme $\mathrm{F}_{420}$ Activity}

The protease and coenzyme $\mathrm{F}_{420}$ activities in the sewage sludge were measured by ultraviolet (UV) spectrophotometry. The protease activity of the sewage sludge was measured according to the procedures given by Whiteley et al., [14]. The sludge $(1.0 \mathrm{~mL})$ was incubated at $37{ }^{\circ} \mathrm{C}$ for $1 \mathrm{~h}$ in a buffer $\left(0.02 \mathrm{~mol} / \mathrm{L} \mathrm{Na}_{2} \mathrm{HPO}_{4}, 0.01 \mathrm{~mol} / \mathrm{L} \mathrm{C}_{6} \mathrm{H}_{8} \mathrm{O}_{7}\right)$ at $\mathrm{pH} 6$ with $2 \%$ azocasein $(1.0 \mathrm{~mL})$. Ice-cold $10 \%$ $(\mathrm{w} / \mathrm{v})$ trichloroacetic acid (TCA) $(1.0 \mathrm{~mL})$ was added to stop the reaction, and the tubes were left at $-20{ }^{\circ} \mathrm{C}$ to facilitate precipitation. The precipitated protein was removed by centrifugation $\left(4000 \times \mathrm{g}\right.$ for $10 \mathrm{~min}$ ), and the $\mathrm{A}_{440} \mathrm{~nm}$ of the TCA-soluble peptides was measured. The coenzyme $\mathrm{F}_{420}$ activity of the sewage sludge was measured according to the procedures given by Whitmore et al., [15]. The sludge was suspended in $0.5 \mathrm{M} \mathrm{NaCl}$ after being centrifuged, and the pellet was suspended in water $(10 \mathrm{~mL})$ and the cells disrupted by heating in a water bath at $100{ }^{\circ} \mathrm{C}$ for $10 \mathrm{~min}$. After cooling, the suspension was centrifuged $(17,000 \times \mathrm{g}$ for $10 \mathrm{~min})$, and the supernatant fluid was diluted 1:2 with $0.3 \mathrm{M} \mathrm{NaC1}$ in $50 \mathrm{n}$-Tris-HC1 buffer ( $\mathrm{pH} 7.5$ ). The solution was then applied to a QAE-Sephadex A-25 column. The eluate was collected, and the absorbance spectrum was measured at $420 \mathrm{~nm}$ with a dual beam spectrophotometer.

\subsubsection{DNA Analysis}

The predominant methanogens in the sludge samples were determined using denaturing gradient gel electrophoresis (DGGE) [16]. The total DNA from the mixed culture was extracted using the phenol-chloroform method and estimated by $1 \%$ agarose gel electrophoresis [17]. The total extracted genomic DNA was used as a template to amplify the V4-5 variable region on 16S rRNA by PCR. The nucleotide sequences of the universal primers were as follows: primer F787, 5'- CGC CCG CCG CGC GCG GCGGGCGGG GCG GGGGCACGGGGG G CGATTAGATACCCSBGTAGTCC -3'; R1059 (5'- GCCATGCACCWCCTCT -3') [18]. The PCR amplification was performed in an automated thermal cycler (Bio-Rad, Hercules, California, USA). Initial denaturation was performed at $94{ }^{\circ} \mathrm{C}$ for $4 \mathrm{~min}$, followed by 30 cycles of denaturation at $94{ }^{\circ} \mathrm{C}$ for $30 \mathrm{~s}$ and annealing at $56{ }^{\circ} \mathrm{C}$ for $1 \mathrm{~min}$. Each annealing step was followed by extension at $72{ }^{\circ} \mathrm{C}$ for $1 \mathrm{~min}$, except for the final 7-min extension step. The PCR products were analyzed by electrophoresis on a 1.5\% (w/v) agarose gel for $30 \mathrm{~min}$ at $120 \mathrm{~V}$ with ethidium bromide in $1 \times$ TAE buffer (40 mMTris acetate, $1 \mathrm{mM}$ EDTA, pH 8.0) [16]. Images of the gel were recorded to determine the size, purity, and concentration of the DNA used by the gene genius bioimaging system [16,17].

DGGE analysis was performed using the DCode Universal Mutation Detection System (Bio-Rad, Hercules, California, USA). The PCR samples were analyzed directly on $8.0 \%(\mathrm{w} / \mathrm{v})$ polyacrylamide gels in $1 \times$ TAE buffer (40 mMTris acetate, 1 mM EDTA, pH 8.0) with a denaturing gradient that 
ranged from $30 \%$ to $60 \%$ (100\% denaturant is $7 \mathrm{M}$ urea and $40 \% \mathrm{v} / \mathrm{v}$ formamide). The gradient gel was cast with a gradient delivery system. Electrophoresis was performed at a constant voltage of $180 \mathrm{~V}$ at $60{ }^{\circ} \mathrm{C}$. After $4 \mathrm{~h}$ of electrophoresis, the gel was stained with ethidium bromide for 30 min and visualized on a UVI transilluminator (U-3010 Hitachi, Tokyo, Japan).

The bands in the gel were excised and rinsed in $1 \mathrm{~mL}$ of deionized water. The gel was crushed in $20 \mu \mathrm{L}$ of sterile deionized water and incubated at $30^{\circ} \mathrm{C}$ for $1 \mathrm{~h}$. The DNA extract was used as a template in the PCR amplification, as described above, and the PCR products were sequenced on an ABI LR-377 DNA sequencer [16]. The sequences of successfully amplified DNA fragments were then compared with the Gen Bank database using the basic local alignment search tool (BLAST) analysis [16].

\section{Results and Discussion}

\subsection{Performance of the $A B R$}

\subsubsection{COD Removal}

The performance of the anaerobic baffled filter reactor was evaluated by the COD removal efficiency throughout the operation of the reactor. The substrate degradation pattern varied as a function of the OLR over an operational period of more than 130 days. Figure 2 presents the COD concentrations of the influent and effluent of each compartment and the COD removal efficiencies during various operations over the study period. During the initial start-up stage, the reactor was operated at a lower OLR to train the sludge to improve the anaerobic environment and sludge activity. The COD removal efficiency was approximately $75 \%$ for sludge acclimatization. This result may have been obtained because the organic matter of the influent was absorbed by the biomass of the soft filler in the initial stage. Up to 30 days of operation, when the influent with a COD concentration of 2000-2500 $\mathrm{mg} / \mathrm{L}$ was applied to the ABR, the effluent COD concentration of the final compartment was lower than $550 \mathrm{mg} / \mathrm{Land}$ and the COD removal efficiency ranged from $75 \%$ to $80 \%$. A gradual improvement in algal degradation was observed, indicating biofilm and granular sludge formation in the reactor. The reactor was operated in the steady state after the anaerobic activated sludge acclimatized over 40 days. Approximately $80 \%$ COD removal occurred when the organic loading rate ranged from 0.26 to $1.2 \mathrm{~kg} \mathrm{COD} /\left(\mathrm{m}^{3} \mathrm{~d}\right)$. Most of the influent COD was removed in Compartments 1 (34\%) and 2 (40\%); a smaller percentage of the influent COD was removed in Compartments $3(25 \%)$ and 4 (23\%), and Compartment 5 removed the remaining fraction of the influent COD (13\%). During the shock stage, temporary acidification occurred in Compartments 1 and 2 during the initial period (Days 102-110) due to the increasing organic loading rate; however, the COD removal of the reactor did not decrease. The COD concentration of the effluent was less than $1500 \mathrm{mg} / \mathrm{L}$ after seven days, indicating that the anaerobic baffled filter reactor possessed greater ability to treat the algae-laden water than indicated by the research by Jing [19]. Jing et al. have disposed of algae with an ABR and obtained an effluent COD concentration of $3500 \mathrm{mg} / \mathrm{L}$ and a removal rate of $55 \%$. In this study, absorption played a dominant role in improving the effluent quality. At first, the organic matter was absorbed on the surface of the soft filler. When the biomass on the soft filler's packing was growing well with high activity, organic matter was absorbed on the algal biomass, which became attached to the soft filler. 
Figure 2. Chemical oxygen demand (COD) removal contributed by each compartment of the reactor.

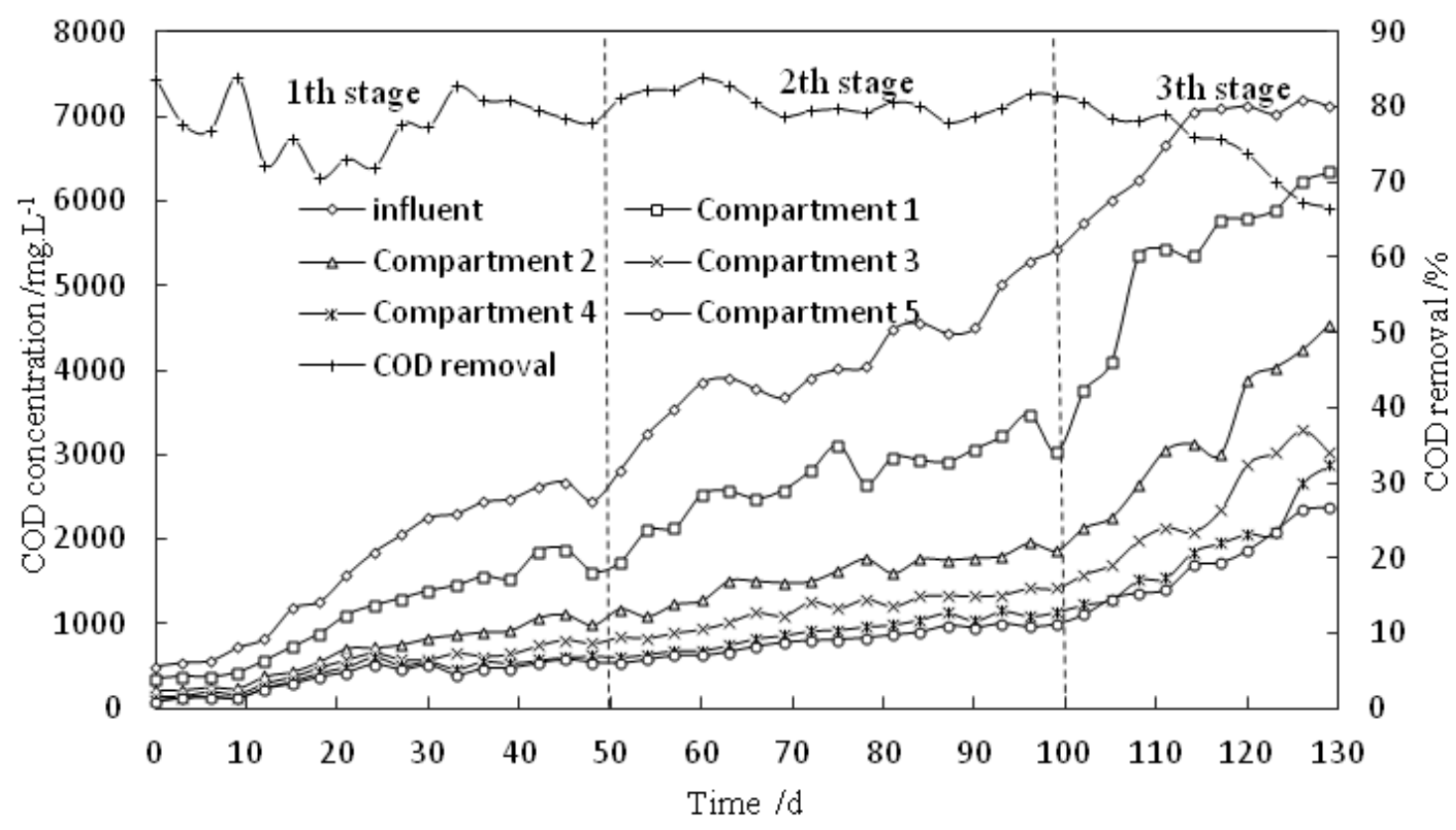

Post-treatment, such as biological contact oxidation and aquatic vegetation wetland use, was studied based on the results of treating the aerobically digested effluent from algae in Taihu Lake. The results indicated that the contact oxidation tank reduced the inlet load of the subsequent aquatic vegetation wetland, and the COD of the average effluent of the combined process was less than $50 \mathrm{mg} / \mathrm{L}$, which satisfied Chinese standard GB18918-2002 for the discharge of pollutants [20].

In the ABR filled with soft filler, Compartments 1 and 2 were important to the treatment of the algae-laden water. These two compartments acted as a buffer zone to all toxic and inhibitory material in the feed, allowing the subsequent compartments to be loaded with a relatively harmless, balanced, and primarily acidified influent [21]. Occasionally, the soft filler played a critical role in intercepting the algae, which prevented both the algae from floating off and encrustation in the compartment.

\subsubsection{Biogas Production}

The performance of the anaerobic reactor was measured in terms of the observed biogas yield and methane content. As shown in Figure 3, the daily total gas production rates were low, with an OLR of $0.05 \mathrm{~kg} \mathrm{COD} /\left(\mathrm{m}^{3} \mathrm{~d}\right)$ during the start-up phase. When the system formed granular sludge during long domestication and cultivation, the biogas production increased with increasing OLR. The biogas production rates varied from 99 to $293 \mathrm{~mL} /(\mathrm{Ld})$, with OLRs ranging from 0.26 to $1.50 \mathrm{~kg} \mathrm{COD} /\left(\mathrm{m}^{3} \mathrm{~d}\right)$.

Gas samples were collected and analyzed every five days during the steady-state phase. In this phase, the gas composition was generally stable, with $\mathrm{CO}_{2}$ concentrations in Compartments 1 and 2 of approximately $45 \%-50 \%$ and $\mathrm{CH}_{4}$ concentrations of $40 \%-48 \%$. In Compartments 3, 4 and 5 , the $\mathrm{CO}_{2}$ concentration decreased to $30 \%$ and the $\mathrm{CH}_{4}$ concentration increased to $55 \%-64 \%$. This result demonstrated the ABR's remarkable phase separation characteristics. In the former compartments, the hydrolysis-acidification reactions of the algae predominated, whereas methanogenesis occurred in the latter compartments. These results demonstrate the feasibility of using algae to produce biogas in an anaerobic baffled filter reactor with microorganisms. 
Figure 3. Impact of the organic loading rate (OLR) on biogas production.

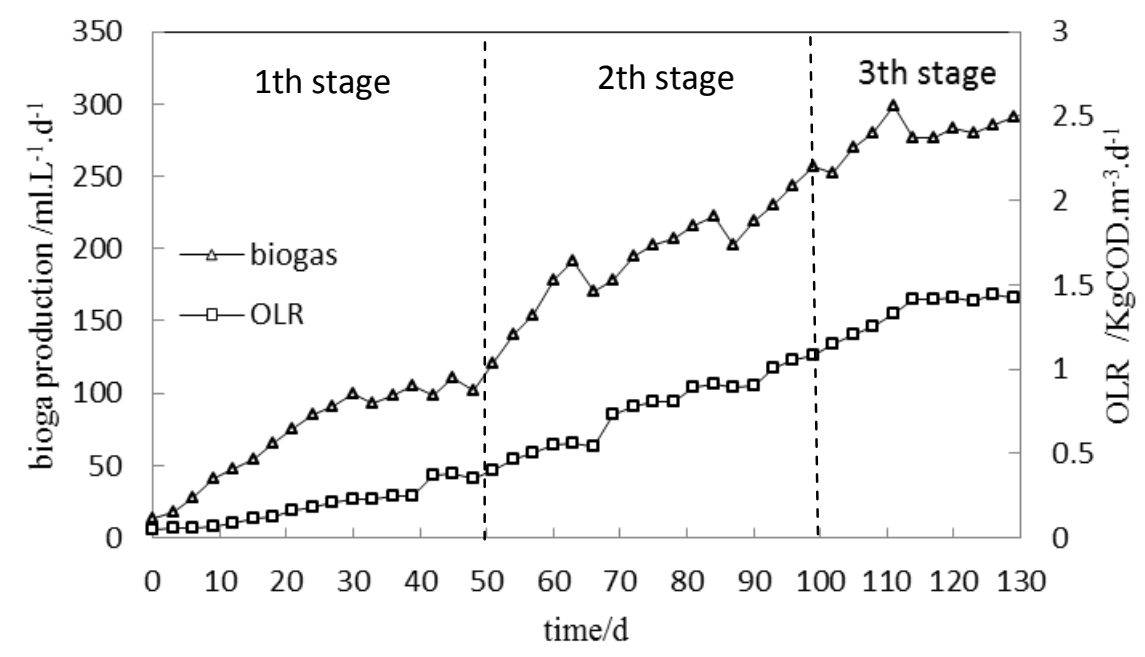

\subsubsection{Microcystin Removal}

Microcystins exist as intracellular compounds in healthy cyanobacteria but are released upon cell lysis [22]. Microcystins pose a health risk to animal and human populations when surface water is used for drinking during post-bloom periods $[23,24]$. The total and extracellular microcystins were monitored each week to demonstrate the efficacy of the anaerobic baffled filter reactor in degrading microcystins.

During the algal bloom, the concentration of microcystins in the algae-laden water salvaged from Taihu Lake was elevated, with concentrations of up to $500 \mu \mathrm{g} / \mathrm{L}$. The concentrations of total microcystin-LR (TMC-LR) and extracellular microcystin-LR (EMC-LR) in the algae-laden water ranged from $326 \mu \mathrm{g} / \mathrm{L}$ to $532 \mu \mathrm{g} / \mathrm{L}$ and $204 \mu \mathrm{g} / \mathrm{L}$ to $321 \mu \mathrm{g} / \mathrm{L}$, respectively. This result indicated that Taihu Lake had been heavily polluted by microcystins due to eutrophication. Figures 4 and 5 illustrate the ability of the reactor to remove TMC-LR and EMC-LR, respectively. The removal rate of TMC-LR in the ABR filled with soft filler ranged from $87.6 \%$ to $94.6 \%$, whereas the removal rate of EMC-LR ranged from $77.4 \%$ to $91.7 \%$. The ABR removed TMC-LR more extensively than EMC-LR, which indicated that dissolved TMC-LR had a superior biodegradation ability compared to EMC-LR.

Figure 4. Total microcystin-loading rate (TMC-LR) removal by the anaerobic baffled filter reactor.

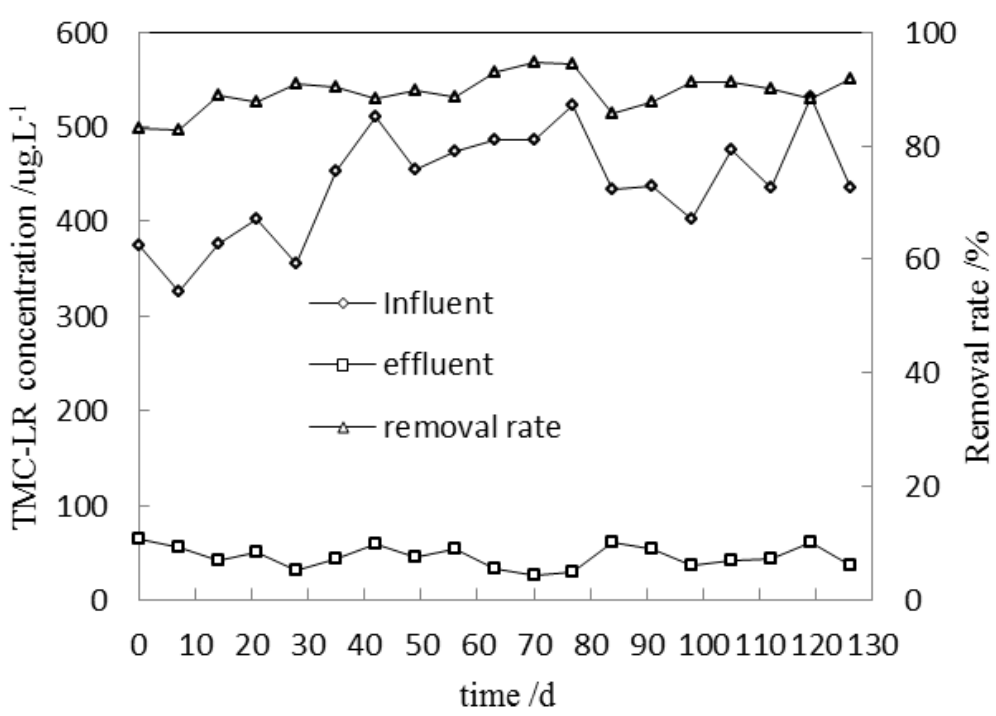


Figure 5. Extracellular microcystin-loading rate (EMC-LR) removal by the anaerobic baffled filter reactor.

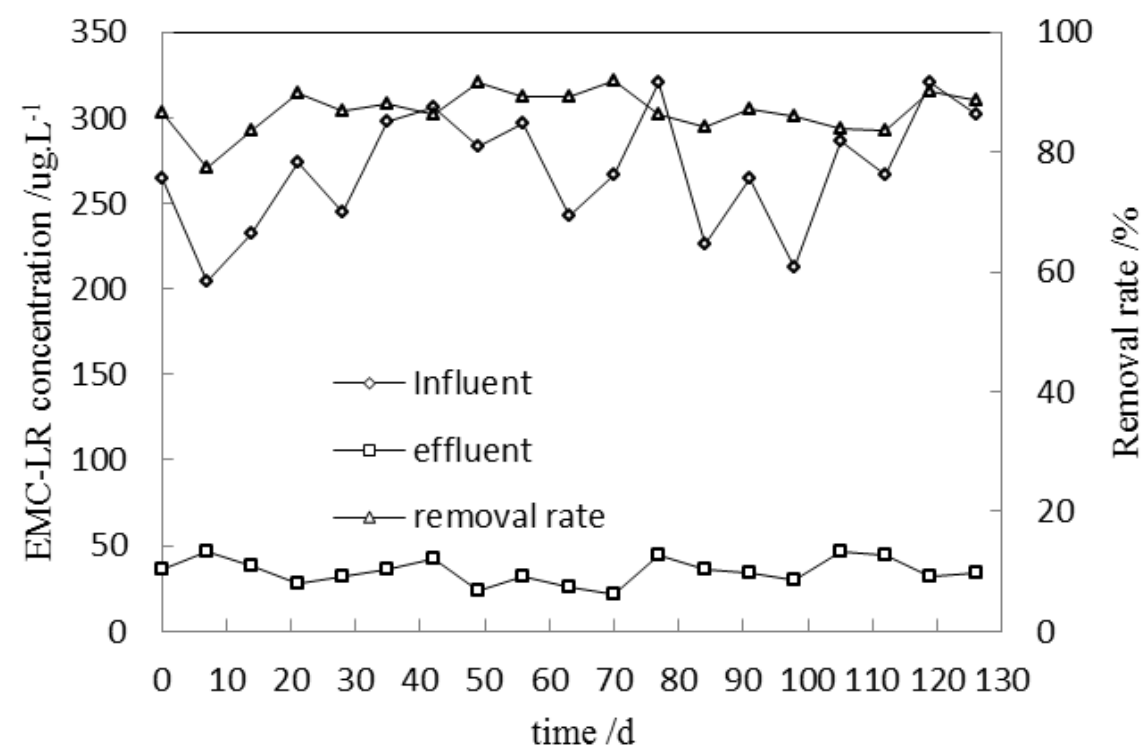

The results of this experiment indicated that the anaerobic baffled filter reactor efficiently removed both TMC-LR and EMC-LR. Because the soft filler had a high specific surface area, it could adsorb and retain more algae in the algae-laden water. In other words, the soft filler increased the HRT of the algae and the total quantity of algae in the filler, allowing additional algae to be removed in the reactor.

\subsection{4. $\mathrm{pH}$, VFAs, and ORP}

$\mathrm{pH}, \mathrm{VFAs}$, and ORP are the key parameters affecting both the anaerobic treatment efficiency and microbial community during anaerobic digestion $[25,26]$. Table 1 provides the $\mathrm{pH}$ and ORP levels, and VFA concentrations in each compartment under various operating conditions. The $\mathrm{pH}$ of the influent fluctuated from 6.35 to 7.05 during the reaction period. In Compartment 1, the $\mathrm{pH}$ dropped from 6.35 to 5.70 over the three stages. However, the $\mathrm{pH}$ levels of Compartments 2, 3, 4 and 5 shifted from $6.76,7.13,7.15$, and 7.20 to $6.60,7.10,7.25$, and 7.40 , respectively. In this study, the relatively low $\mathrm{pH}$ values in Compartments 1 and 2 indicated that the substrates in the anaerobic digestion had hydrolyzed to simple organics, which were fermented to VFAs by the acidogens, acidogenesis, and acetogenesis occurring in these compartments. The $\mathrm{pH}$ values in Compartments 3, 4 and 5 were maintained at constant levels due to the effective consumption of VFAs. This result demonstrated that the VFAs had been converted to acetate and $\mathrm{H}_{2}$ gas by acetogens, and these intermediates were then converted to $\mathrm{CH}_{4}$ by methanogens in the subsequent compartments [27,28]. The anaerobic baffled filter reactor configuration promoted phase separation, and reactor souring did not occur at any time during the operating period.

The ORP, which is a factor in anaerobic digestion, affects the activity of methanobacteria. As shown in Table 1, the ORP value decreased in every compartment over the three stages, from approximately $-190 \mathrm{mV}$ in Compartment 1 to approximately $-312 \mathrm{mV}$ in Compartment 5 during the first stage. During the third stage, the ORP decreased from $-252 \mathrm{mV}$ in Compartment 1 to $-341 \mathrm{mV}$ in Compartment 5. The optimal ORP for methane oxidizing activity is approximately $-330 \mathrm{mV}$ [26]. The 
ORP values in these compartments had previously been thought to be maintained at a constant level without manual intervention.

Table 1. Variation of $\mathrm{pH}$, volatile fatty acids (VFAs), and oxidation-reduction potential (ORP) in the (anaerobic baffled reactor) ABR.

\begin{tabular}{cccccccc}
\hline Stages & Indexes & Influent & Compartment 1 & Compartment 2 & Compartment 3 & Compartment 4 & Compartment 5 \\
\hline \multirow{2}{*}{ First stage } & $\mathrm{pH}$ & $6.70 \pm 0.35$ & $6.35 \pm 0.23$ & $6.76 \pm 0.25$ & $7.13 \pm 0.34$ & $7.15 \pm 0.25$ & $7.20 \pm 0.23$ \\
steady state & VFAs $(\mathrm{mg} / \mathrm{L})$ & - & $800 \pm 65$ & $650 \pm 43$ & $325 \pm 35$ & $227 \pm 25$ & $205 \pm 27$ \\
& ORP $(\mathrm{mV})$ & - & $-190 \pm 34$ & $-250 \pm 21$ & $-284 \pm 15$ & $-302 \pm 17$ & $-312 \pm 13$ \\
Second & $\mathrm{pH}$ & $6.70 \pm 0.35$ & $6.05 \pm 0.21$ & $6.80 \pm 0.17$ & $7.15 \pm 0.07$ & $7.28 \pm 0.06$ & $7.30 \pm 0.05$ \\
stage & VFA $(\mathrm{mg} / \mathrm{L})$ & - & $1800 \pm 165$ & $970 \pm 84$ & $440 \pm 38$ & $320 \pm 34$ & $170 \pm 25$ \\
steady state & ORP $(\mathrm{mV})$ & - & $-247 \pm 25$ & $-297 \pm 18$ & $-313 \pm 21$ & $-318 \pm 15$ & $-325 \pm 11$ \\
& $\mathrm{pH}$ & $6.70 \pm 0.35$ & $5.70 \pm 0.19$ & $6.60 \pm 0.16$ & $7.10 \pm 0.08$ & $7.25 \pm 0.03$ & $7.40 \pm 0.03$ \\
Third stage & $\mathrm{VFA}(\mathrm{mg} / \mathrm{L})$ & - & $4450 \pm 187$ & $1740 \pm 93$ & $680 \pm 72$ & $480 \pm 32$ & $240 \pm 26$ \\
steady state & ORP $(\mathrm{mV})$ & - & $-252 \pm 23$ & $-317 \pm 19$ & $-325 \pm 12$ & $-334 \pm 17$ & $-341 \pm 13$ \\
\hline
\end{tabular}

The highest VFA concentration was observed in the first compartment and increased in every compartment. The VFA concentration also decreased longitudinally along the reactor. This behavior demonstrated that hydrolysis and acidogenesis were the main biochemical activities occurring in the first few compartments, whereas methanogenesis dominated in the last few compartments.

\subsection{Scanning Electron Microscopy (SEM) Analysis of Microbial Morphologies in the Reactor}

The sludge in each compartment was observed 40 days after the start-up of the reactor using SEM, as illustrated in Figure 6A-E. The sludge and microscopic results indicated rich biofacies, whereas the dominant cells appeared to have different morphologies in each compartment of the reactor. Different bacterial morphologies were also observed within the reactor. In Compartment 1, the microbial structure developed a heterogeneous colonization pattern composed mainly of cocci and bacilli of varying sizes and shapes, and hydrolyzing and acid-producing microorganisms predominated. There were no predominant bacteria in Compartment 2. As shown in Figure 6B, cocci, bacilli, and filamentous microorganisms adhered to the sludge. Based on their bionomics, the acidogenic bacteria and methanogens could potentially coexist in this compartment. The microorganisms in the latter compartments of the reactor were unitary and primarily cocci, as illustrated in Figure $6 \mathrm{C}-\mathrm{E}$. These cocci resembled species of the Methanococcus genus. The number of smaller cocci decreased from Compartments 3 to 5, whereas the number of larger cocci increased from Compartments 3 to 5. There were numerous holes in the granular sludge that allowed gas to escape and matter to be removed.

The unique flow characteristics of the anaerobic baffled filter reactor allowed different bacterial populations to dominate in each compartment. Therefore, the microbial morphology differed in each compartment. Acidogenesis and methanogenesis were separated longitudinally, allowing the reactor to behave as a two-phase system without the associated control problems and high costs [29]. In addition, the anaerobic baffled filter reactor promoted microbial enrichment and selection by producing biofilm sludge and granular sludge [30]. 
Figure 6. Scanning electron microscopy (SEMs) illustrating the different types of bacteria in the granular sludge from Compartments 1 to 5, respectively. (A) Compartment 1; (B) Compartment 2; (C) Compartment 3; (D) Compartment 4; (E) Compatment 5.
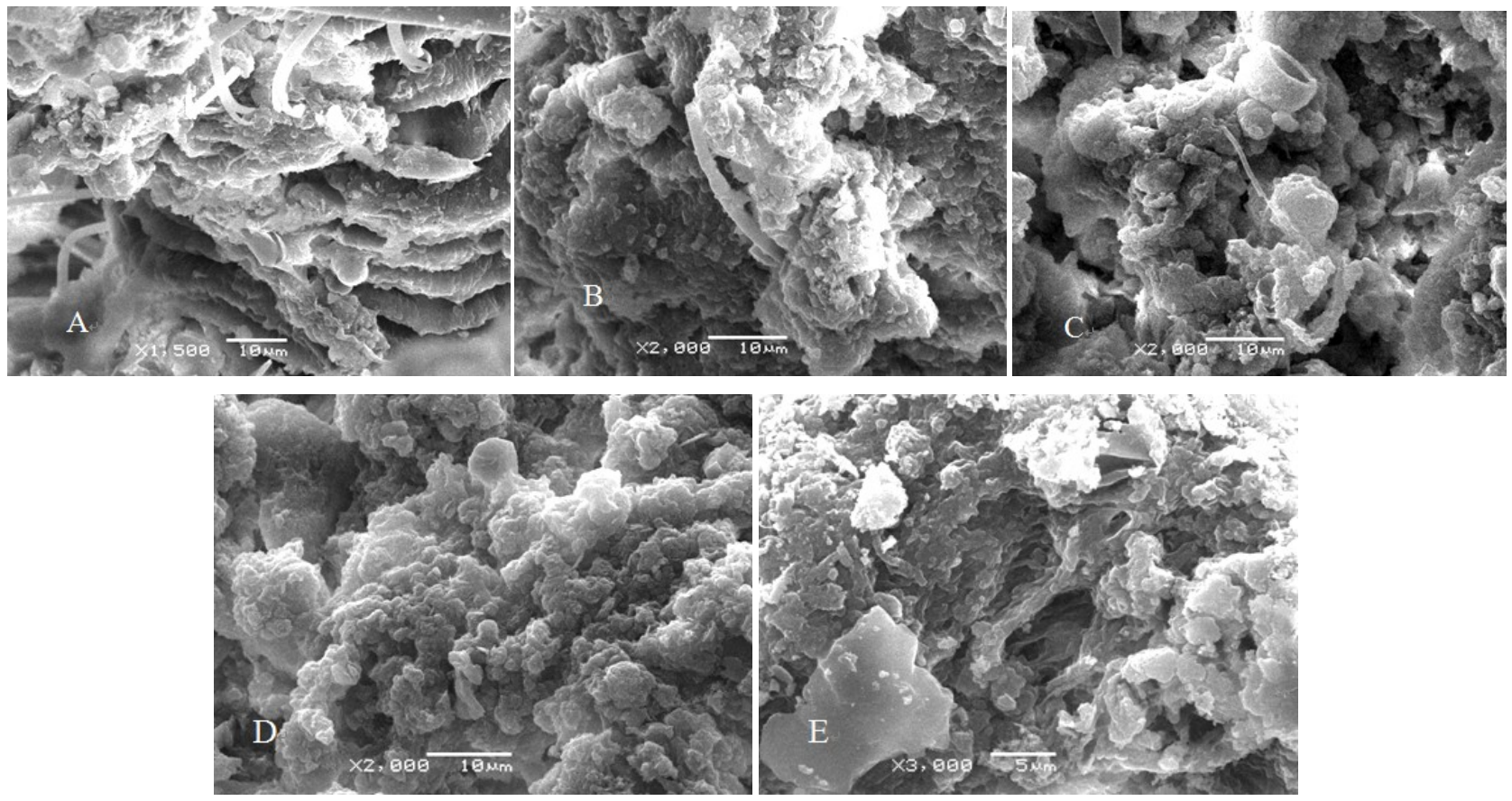

\subsection{Archaeal Denaturing Gradient Gel Electrophoresis (DGGE) Analysis}

The DGGE approach has been widely used in environmental microbiology to study microbial community structures in complex systems, including anaerobic bioreactors in the laboratory [31-33]. Archaeal community fingerprints from each compartment on the sampling dates (on Days 2 and 100) were generated by DGGE analysis of the V5-6 region of 16S rDNA (Figure 7). Thirteen bands, designated Ad1-13, were purified for subsequent sequencing analyses. The band numbers and intensities of the DGGE community fingerprints changed as the operation of the reactor proceeded. The community structures of the samples from the five compartments on Day 2 were similar because the reactor was allowed to reach the stationary phase for 10 days to stimulate biofilm growth on the soft filler in each compartment. The DGGE graph illustrates that Ad1, Ad5, Ad8, and Ad9 were predominant in each compartment of the ABR filled with soft filler on Day 2. Ad1 and Ad8 were closely related to Methanoregula species, with $97.5 \%$ and $90.2 \%$ similarities, respectively.

The microbial community structure and function changed concomitantly during the reactor's operation, and the biomass had sufficient time to adjust and perform more efficiently [34]. Ad3, Ad4, Ad10, Ad11, Ad12, and Ad13 were detected only on Day 100 in the reactor. Two of these species (Ad3 and Ad11) were closely related to Methanobacteriaceae, with approximately $92.1 \%-95.8 \%$ similarities, respectively. Ad7 was closely related to Methanoculleus, with $90.2 \%$ similarity, and Methanoculleus has been previously reported in sludge samples obtained from an EGSB [35]. 
Figure 7. Denaturing gradient gel electrophoresis (DGGE) fingerprints from each compartment of the reactor on Days 2 and 100.
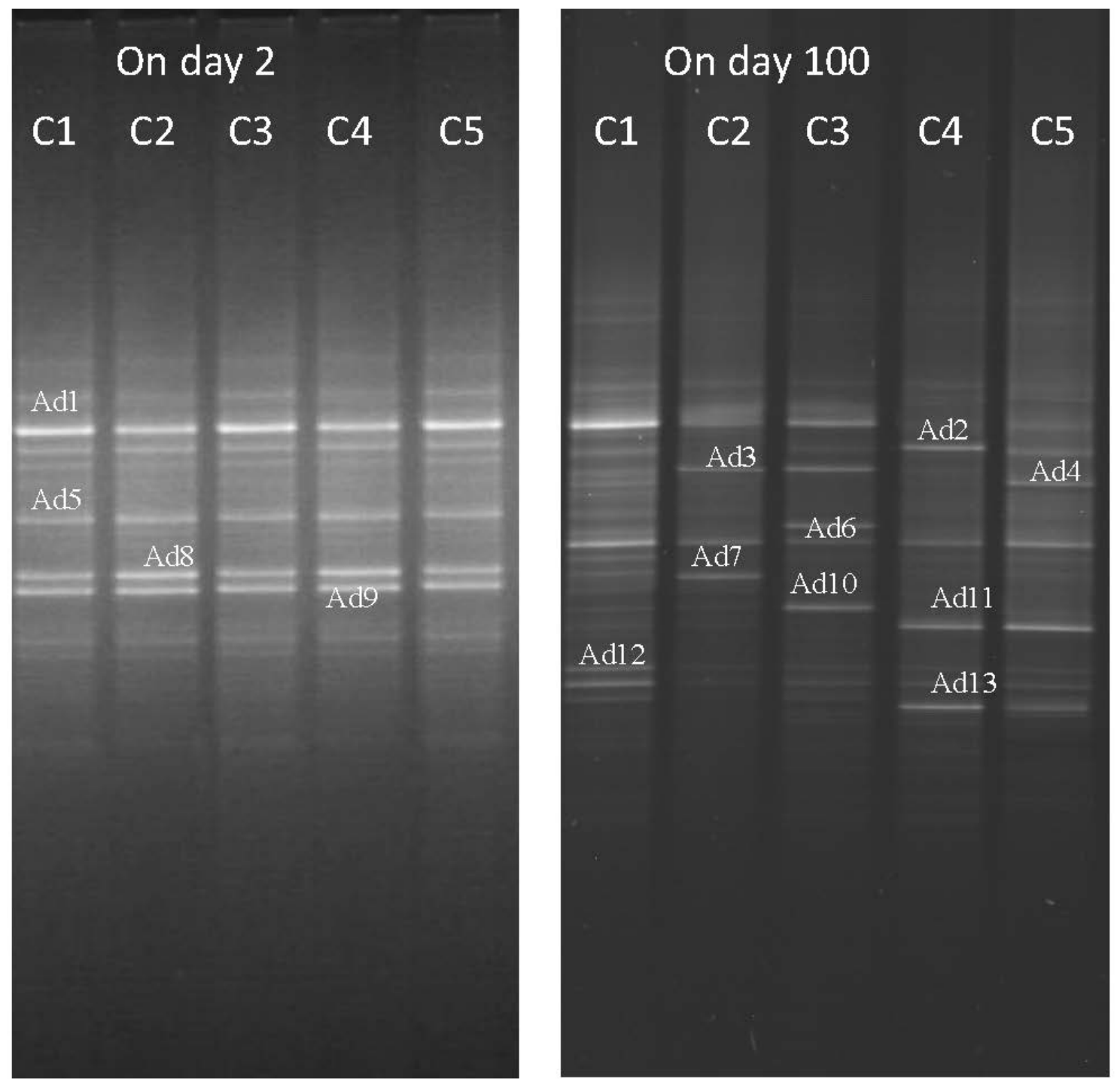

Table 2 presents the phylogenetic affiliations of the band sequences, which were determined by comparison with the Gen Bank database. The DGGE community fingerprints in the samples varied in terms of band number and intensity in each compartment on day 100. The most distinct spatial community succession was detected on day 100, and a clear difference existed between the reactor's anterior and posterior compartments. All of the sequences from the archaeal libraries matched with methanogens of the phylum Euryarchaeota and could be classified into five genera: Methanoregula, Methanobacteriaceae, Methanosaeta, Methanoculleu, and Thermogymnomonas. Ad1 and Ad2 were affiliated with Methanoregula, as previously observed in anaerobic sludge [36].

The anterior (Compartments 1 and 2) of the reactor was able remove COD with high efficiency (Figure 2) because microbial organisms with the ability to hydrolyze substances existed in this section of the ABR. Other researchers have observed that some microbial organisms are able to degrade solvents and VFAs through their physiological functions and phylogeny [37,38]. The methanation reaction was the main reaction occurring in the posterior (Compartments 4 and 5) of the ABR, and an abundance of Methanoregula, Methanobacteriaceae, and Thermogymnomonas (Ad2, Ad11, and Ad13, 
respectively) was detected in Compartments 4 and 5 on day 100. The anaerobic baffled filter reactor, combined with the biofilm attached to the soft filler and the granular sludge suspended at the bottom of the reactor, promoted microbial selection and zoning. These observations demonstrated that biological phase separation occurred in the ABR. It was unlikely that a complete separation of phases (acidogenic and methanogenic) occurred within the ABR because methanogens were observed in all compartments.

Table 2. Identity of the genomic sequences in the dominant DGGE bands obtained by sequencing and basic local alignment search tool (BLAST) analysis.

\begin{tabular}{ccccc}
\hline Band & Nearest species and taxon & $\begin{array}{c}\text { Phylogenetic affiliation } \\
\text { to family or genus level }\end{array}$ & $\begin{array}{c}\text { Similarity } \\
(\mathbf{\%})\end{array}$ & Access No. \\
\hline Ad1 & Candidatus Methanoregulaboonei & Methanoregula & 97.5 & EU887810 \\
& Methanoregulaformicica & Methanoregula & 92.1 & AB479390 \\
Ad2 & Methanomicrobialesarchaeon & Methanoregula & 95.6 & AB236088 \\
Ad3 & uncultured archaeon & Methanobacteriaceae & 92.1 & EU155919 \\
Ad4 & Candidatus Methanoregulaboonei & Methanoregula & 96.5 & EU887826 \\
Ad5 & uncultured euryarchaeote & Methanoregula & 90.2 & DQ676264 \\
& uncultured archaeon & Methanoregula & 90.2 & EU155924 \\
Ad6 & toluene-degrading methanogenic & Methanosaeta & 95.1 & AF423188 \\
& consortium archaeon & Methanosaeta & 93.2 & EU888815 \\
Ad7 & uncultured Methanosaeta sp. & Methanoculleus & 90.2 & FR832414 \\
Ad8 & uncultured archaeon & Methanosaeta & 91.6 & X16932 \\
Ad9 & Methanosaetaconcilii & Methanobacteriaceae & 94.7 & AF424765 \\
Ad10 & Methanosphaera sp. & Methanobacteriaceae & 91.7 & AB266909 \\
Ad11 & uncultured bacterium & Methanosaeta & 93.7 & X51423 \\
Ad12 & uncultured Thermoplasmatalesarchaeon & Thermogymnomonas & 95.1 & EU731598 \\
Ad13 & uncultured archaeon & Methanoculleus & 92 & FR832414 \\
& Thermoplasmatalesarchaeon & Thermogymnomonas & 90.1 & GNA10F01 \\
\hline
\end{tabular}

\subsection{Enzyme Activity Analysis}

The activities of enzymes, such as those of protease and coenzyme $\mathrm{F}_{420}$, have been extensively studied in anaerobic digestion [14]. These activities play a significant role in the decomposition of substrates, affecting nutrients and nutrient availability. Microbial enzyme activities are associated with microbial metabolism [39]. The coenzyme $\mathrm{F}_{420}$ is widely distributed in methanogenia [15].

The results of this study suggest that the activity of the protease in the reactor increased in each compartment over the study period (Figure 8 ). The protease activity decreased longitudinally along the reactor from Compartments 1 to 5. The highest protease activity was observed in the first compartment, with average values of $27 \mu \mathrm{mol} /(\mathrm{min} \cdot \mathrm{g})$ in Compartment $1,25 \mu \mathrm{mol} /(\mathrm{min} \cdot \mathrm{g})$ in Compartment 2, $22 \mu \mathrm{mol} /(\mathrm{min} \cdot \mathrm{g})$ in Compartment 3, and less than $3 \mu \mathrm{mol} /(\mathrm{min} \cdot \mathrm{g})$ in Compartments 4 and 5 . The protease activity demonstrated that hydrolysis and acidogenesis were the main biochemical reactions occurring in the first few compartments. These observations suggest that the ABR system facilitated systematic selection in the different compartments to promote phase separation. 
Figure 8. Variation in protease activity in the reactor.

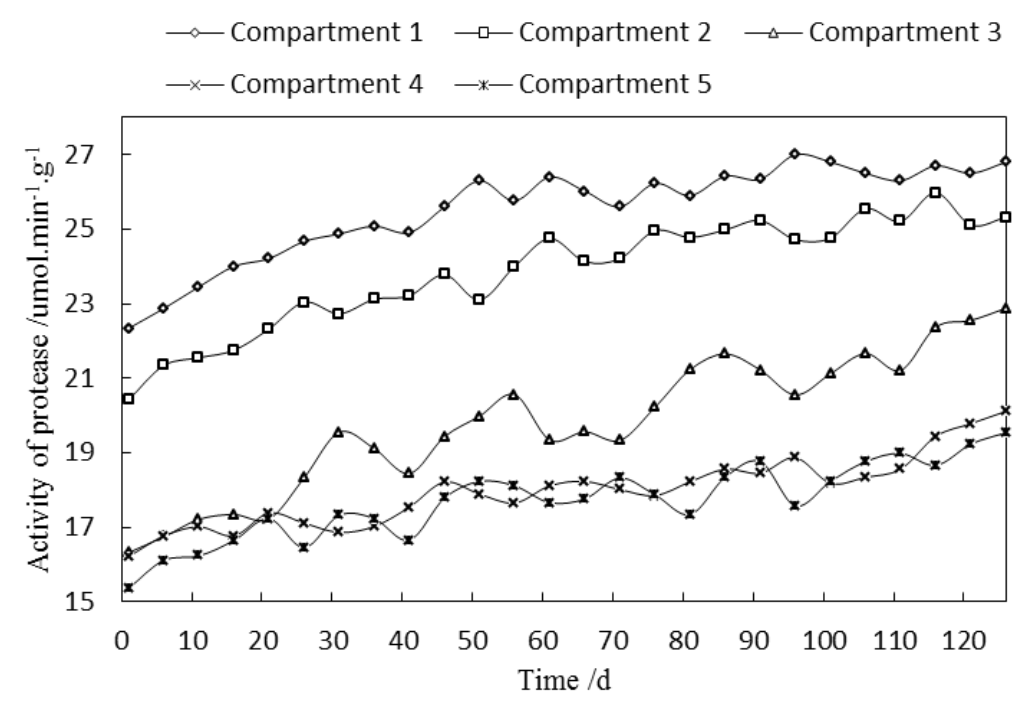

As shown in Figure 9, the activity of coenzyme $\mathrm{F}_{420}$ clearly increased during the adaptive transient period of the methanogens after inoculation. The results of the treatment indicate that the coenzyme $\mathrm{F}_{420}$ activities in Compartments 3, 4 and 5 were higher than those in Compartments 1 and 2.

Figure 9. Variation in coenzyme $\mathrm{F}_{420}$ activity in the reactor.

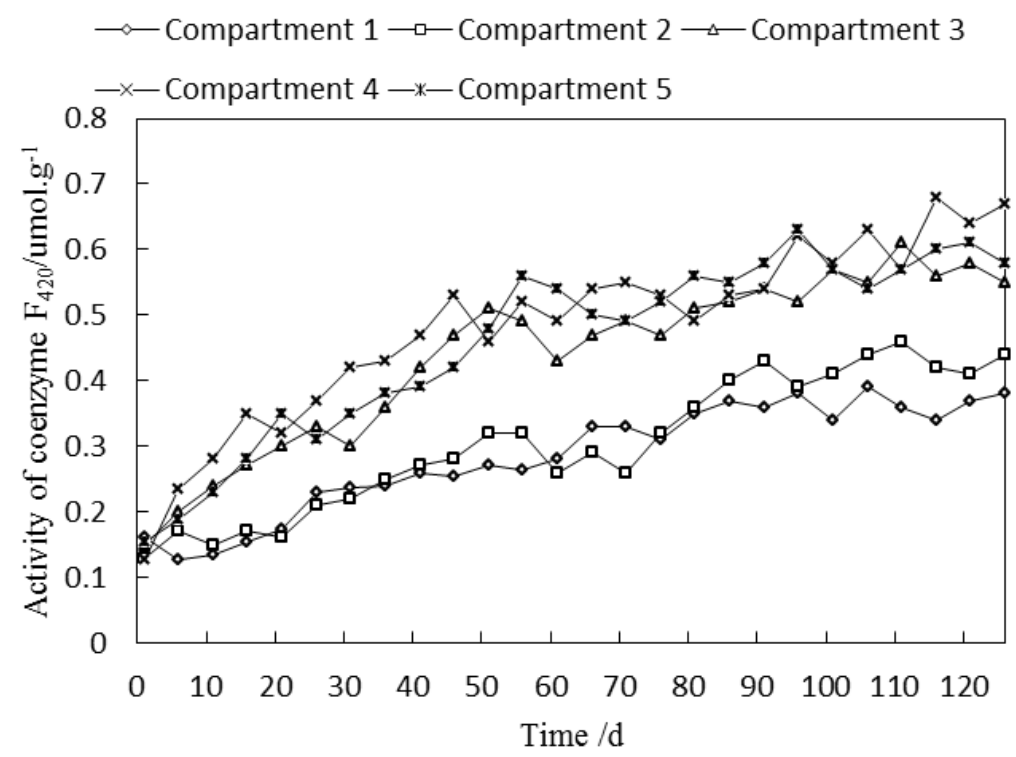

This behavior indicated that methanogenesis was also dominant in the last few compartments. It was unlikely that a complete separation of phases (acidogenic and methanogenic) occurred within the $\mathrm{ABR}$ because protease and coenzyme $\mathrm{F}_{420}$ were detected in all compartments.

\section{Conclusions}

The main objectives of this study were to examine the treatment of algae-laden water using an anaerobic baffled filter reactor and to elucidate the microbial phase in the system during the experiments. The algae-laden water was treated with an OLR of approximately $1.5 \mathrm{~kg} \mathrm{COD} /\left(\mathrm{m}^{3} \mathrm{~d}\right)$ at an HRT of five days and an ambient temperature of $30 \mathrm{C}$, which resulted in an $80 \%$ COD removal 
efficiency and a $293 \mathrm{~mL} /(\mathrm{Ld})$ biogas production rate. The spatiotemporal community succession patterns were altered, and the DGGE community fingerprints in the samples differed with respect to band number and intensity in each compartment on day 100 but were similar on Day 2. Moreover, five dominant sequence genera, Methanoregula, Methanobacteriaceae, Methanosaeta, Methanoculleu, and Thermogymnomonas, were detected in the sludge and classified by DGGE.

The anaerobic baffled filter reactor, combined with the biofilm sludge attached to the soft filler and granular sludge suspended at the bottom of the reactor, promoted microbial selection and zoning. The protease activity in the reactor decreased longitudinally along the reactor from Compartments 1 to 5, but the activity of coenzyme $\mathrm{F}_{420}$ increased. The anaerobic baffled filter reactor developed in this study was concluded to be an efficient reactor configuration for the treatment of algae-laden water. Post-treatment, such as biological contact oxidation and aquatic vegetation wetland use, was required to treat the anaerobic effluent and satisfy Chinese standard GB18918-2002 for the discharge of pollutants.

\section{Acknowledgments}

This work was supported by the National Major Projects of Water Pollution Control and Management Technology of China (2012ZX07101-005), National Natural Science Foundation of China (51009027) and the research fund of the Key Laboratory for Advanced Technology in Environmental Protection of Jiangsu Province.

\section{Conflicts of Interest}

The authors declare no conflict of interest.

\section{References}

1. Eleuterio, L.; Batist, J.R. Biodegradation studies and sequencing of microcystin-LR degrading bacteria isolated from a drinking water biofilter and a fresh water lake. Toxicon 2010, 55, 1434-1442.

2. Guo, L. Doing battle with the green monster of Taihu lake. Science 2007, 317, doi:10.1126/science.317.5842.1166.

3. Yan, Q.; Zhao, M.; Miao, H.; Ruan, W.; Song, R. Coupling of the hydrogen and polyhydroxyalkano-ates (PHA) production through anaerobic digestion from Taihu blue algae. Bioresour. Technol. 2010, 101, 4508-4512.

4. Cai, Y.; Kong, F.; Shi, L.; Yu, Y. Spatial heterogeneity of cyanobacterial communities and genetic variation of Microcystis populations within large, shallow eutrophic lakes (Lake Taihu and Lake Chaohu, China). J. Environ. Sci. 2012, 24, 1832-1842.

5. Liu, Y.; Chen, W.; Li, D.; Huang, Z.; Shen, Y.; Liu, Y. Cyanobacteria-cyanotoxin-contaminations and eutrophication status before Wuxi Drinking Water Crisis in Lake Taihu, China. J. Environ. Sci. 2011, 23, 575-581.

6. Wu, B.; Zhao, D.; Zhang, Y.; Zhang, X.; Cheng, S. Multivariate statistical study of organic pollutants in Nanjing reach of Yangtze River. J. Hazard. Mater. 2009, 169, 1093-1098. 
7. Kuscu, O.S.; Sponza, D.T. Performance of anaerobic baffled reactor (ABR) treating synthetic wastewater containing p-nitrophenol. Enzym. Microb. Technol. 2005, 36, 888-895.

8. Uyanik, S.; Sallis, P.J.; Anderson, G.K. The effect of polymer addition on granulation in an anaerobic baffled reactor (ABR). Part 1: Process performance. Water Res. 2002, 36, 933-943.

9. Ji, R.P.; Lu, X.W.; Li, X.N.; Pu, Y.P. Biological degradation of algae and microcystins by microbial enrichment on artrificial media. Ecol. Eng. 2009, 35, 1584-1588.

10. Bachmann, A.; Beard, V.L.; McCarty, P.L. Performance characteristics of the anaerobic baffled reactor. Water Res. 1985, 19, 99-106.

11. State Environmental Protection Administration of China. National Standard Methods for Water and Wastewater Quality Analysis, 4th ed.; China Environmental Science Press: Beijing, China, 2004; pp. 102-226.

12. Liu, R.; Lu, X.; Tian, Q.; Yang, B.; Chen, J. The performance evaluation of hybrid anaerobic baffled reactor for treatment of PVA-containing desizing wastewater. Desalination 2011, 271, 287-294.

13. Zhu, G.-F.; Li, J.-Z.; Wu, P.; Jin, H.-Z.; Wang, Z. The performance and phase separated characteristics of an anaerobic baffled reactor treating soybean protein processing wastewater. Bioresour. Technol. 2008, 99, 8027-8033.

14. Whiteley, C.G.; Heron, P. The enzymology of sludge solubilisation utilizing sulphate reducing systems properties of proteases and phosphatases. Enzym. Microb. Technol. 2001, 31, 419-424.

15. Whitmore, T.N.; Etheridge, S.P.; Stafford, D.A.; Leroff, U.E.A.; Hughes, D. The evaluation of anaerobic digester performance by coenzyme $\mathrm{F}_{420}$ analysis. Biomass 1986, 9, 29-35.

16. Arooj, M.F.; Han, S.-K.; Kim, S.-H.; Kim, D.-H.; Shin, H.-S. Sludge characteristics in anaerobic SBR system producing hydrogen gas. Water Res. 2007, 41, 1177-1184.

17. Mohan, S.V.; Raghavulu, S.V.; Goud, R.K.; Srikanth, S.; Babu, V.L.; Sarma, P.N. Microbial diversity analysis of long term operated biofilm configured anaerobic reactor producing biohydrogen from wastewater under diverse conditions. Int. J. Hydrog. Energy 2010, 35, 12208-12215.

18. Yu, Y.; Lü, X.; Li, J. Start-up of improved external circulation anaerobic reactor treating cyanobacteria and microbial properties of granular sludge. CIESC J. 2013, 64, 4203-4219.

19. Du, J.; Yan, S.-H.; Chang, Z.-Z. Potential of methane production of blue algae and its feasibility of fermentation with anaerobic baffled reactor. Jiangsu Agric. Sci. 2008, 24, 948-953.

20. Yu, Y.; Lü, X.; Wu, Y.; Xu, W.; Zhao, J.-W. Research on combined process of biological contact oxidation and aquatic vegetable wetland for algae anaerobically digested effluent treatment. J. Cent. South Univ. Nat. Sci. 2013, 40, 87-92.

21. Uyanik, S.; Sallis, P.J.; Anderson, G.K. The effect of polymer addition on granulation in an anaerobic baffled reactor (ABR). Part II: Compartmentalization of bacterial papulations. Water Res. 2002, 36, 944-955.

22. Holst, T.; Jorgensen, N.O.; Jorgensen, C.; Johansen, A. Degradation of microcystin in sediments at oxic and anoxic, denitrifying conditions. Water Res. 2003, 37, 4748-4760.

23. Falconer, I.R.; Humpage, A.R. Health risk assessment of cyanobacterial (blue-green algal) toxins in drinking water. Int. J. Environ. Res. Publ. Health 2005, 2, 43-50.

24. Nasri, H.; El Herry, S.; Bouaicha, N. First reported case of turtle deaths during a toxic Microcystis spp. bloom in Lake Oubeira, Algeria. Ecotoxicol. Environ. Safe 2008, 71, 535-544. 
25. Mensah, K.A.; Forster, C.F. An examination of the effects of detergents on anaerobic digestion. Bioresour. Technol. 2003, 90, 133-138.

26. Ren, N.Q.; Zhao, D.; Chen, X.L.; Li, J.Z. Mechanism and controlling strategy of the production and accumulation of propionic acid for anaerobic wastewater treatment. Sci. China B 2002, 45, 319-327.

27. Speece, R.E. Anaerobic Biotechnology for Industrial Wastewater; Archae Press: Nashville, TN, USA, 1996; pp. 45-49.

28. Dolfing, J.; Bloeman, W.G.B.M. Activity measurements as a tool to characterize the microbial composition of methanogenic environments. J. Microbiol. Methods 1985, 4, 1-12.

29. Barber, W.P.; Stuckey, D.C. The use of the anaerobic baffled reactor (ABR) for wastewater treatment: A review. Water Res. 1999, 33, 1559-1578.

30. Angenent, L.T.; Abel, S.J.; Sung, S. Effect of an organic shock load on the stability of an anaerobic migrating blanket reactor. J. Environ. Eng. 2002, 128, 1109-1120.

31. Lee, C.; Kim, J.; Shin, S.G.; Hwang, S. Monitoring bacterial and archaeal community shifts in a mesophilic anaerobic batch reactor treating a high-strength organic wastewater. FEMS Microbiol. Ecol. 2008, 65, 544-554.

32. Diaz, E.E.; Stams, A.J.A.; Amils, R.; Sanz, J.L. Phenotypic properties and microbial diversity of methanogenic granules from a full-scale upflow anaerobic sludge bed reactor treating brewery wastewater. Appl. Environ. Microbiol. 2006, 72, 4942-4949.

33. Bialek, K.; Kim, J.; Lee, C.; Collins, G.; Mahony, T.; O’Flaherty, V. Quantitative and qualitative analyses of methanogenic community development in high-rate anaerobic bioreactors. Water Res. 2011, 45, 1298-1308.

34. Liu, X.; Ren, N.; Yuan, Y. Performance of a periodic anaerobic baffled reactor fed on Chinese traditional medicine industrial wastewater. Bioresour. Technol. 2009, 100, 104-110.

35. Collins, G.; Woods, A.; McHugh, S.; Carton, M.W.; OFlaherty, V. Microbial community structure and methanogenic activity during start-up of psychrophilic anaerobic digesters treating synthetic industrial wastewaters. FEMS Microbiol. Ecol. 2003, 46,159-170.

36. Watanabe, R.; Tada, C.; Baba, Y.; Fukuda, Y.; Nakai, Y. Enhancing methane production during the anaerobic digestion of crude glycerol using Japanese cedar charcoal. Bioresour. Technol. 2013, 150, 387-392.

37. Zhang, J.; Wei, Y.; Xiao, W.; Zhou, Z.; Yan, X. Performance and spatial community succession of an anaerobic baffled reactor treating acetone-butanol-ethanol fermentation wastewater. Bioresour. Technol. 2011, 102, 7407-7414.

38. Nachaiyasit, S.; Stuckey, D.C. The effect of shock loads on the performance of an anaerobic baffled reactor (ABR). 2. Step and transient hydraulic shocks at constant feed strength. Water Res. 1997, 31, 2747-2754.

39. Aoki, K.; Miyamoto, K.; Murakami, S. Anaerobic synthesis of extracellular proteases by the soil bacterium bacillus sp.AM-23: Purification and characterization of the enzymes. Soil Biol. Biochem. 1995, 27, 1377-1382.

(C) 2014 by the authors; licensee MDPI, Basel, Switzerland. This article is an open access article distributed under the terms and conditions of the Creative Commons Attribution license (http://creativecommons.org/licenses/by/3.0/). 